\title{
Özgün araştırma makalesi \\ İki farklı endodontik cetvelin (endoblok) cetvel ve kalibrasyon deliklerinin ölçüm doğruluklarının incelenmesi
}

\author{
Olga Yücel iD, ${ }^{1}$ Esma Sarıçam (iD, ${ }^{2 *}$ \\ Bülent Altunkaynak iD, ${ }^{3}$ Güven Kayaoğlu (iD ${ }^{1}$ \\ ${ }^{1}$ Endodonti Anabilim Dalı, Diş Hekimliği Fakültesi, \\ Gazi Universitesi, ${ }^{2}$ Endodonti Anabilim Dalı, \\ Diş Hekimliği Fakültesi, Ankara Yıldırım Beyazıt Üniversitesi, \\ ${ }^{3}$ Istatistik Bölümü, Fen Fakültesi, Gazi Üniversitesi, \\ Ankara, Türkiye

\section{ÖZET}

AmAÇ: Endoblok, endodonti pratiğinde çalışma boyunun tespiti ve sürdürülmesinde yararlanılan odontometrik bir araçtır. Bu çalışmada biri yerli üretim olmak üzere 2 farklı endobloğun milimetrik olarak doğruluğunun değerlendirilmesi amaçlandı.

Gereç ve Yöntem: Mini-Endo-Bloc (Dentsply-Maillefer, Ballaigues, İsviçre) ve Resident (Kibar Dental, İstanbul, Türkiye) marka endobloklardan üçer adet alındı. Bu endoblokların cetvelleri üzerinde bulunan milimetre çizgileri (12-30 arası), doğrudan $0.01 \mathrm{~mm}$ hassasiyetinde bir elektronik kumpas ile ölçüldü. Eğe boyu kalibrasyon deliklerinin derinlikleri (12.0-27.5 arası) ise, lastik stoperli \#40 bir eğeye transfer edilerek yine aynı kumpas ile ölçüldü. Her bir paralel beş kez ölçüldü. Her bir endoblok markasının ölçüm kalitesinin incelenmesi için istatistiksel kontrol sınırları ile spesifikasyon sınırları karşılaştırıldı. Spesifikasyon sınırları ürün üzerinde belirtilen referans değerler dikkate alınarak 3 standart sapma (sigma) genişliğinde hesaplandı. Kontrol sınırları ise, ürünün test edilmesi sırasında elde edilen ölçümlerden hesaplandı. Kontrol sınırlarının spesifikasyon sınırlarını aşması durumu hata olarak kabul edildi.

BULGULAR: Mini-Endo-Bloc'un cetvelinde ve kalibrasyon deliklerinde hata görülmedi. Resident'in ise $23,25-30 \mathrm{~mm}$ cetvel çizgilerinde (referans değerinin üstünde ölçümler) ve $15.0,18.0,18.5$ ve 19.0 numaralı deliklerinde (referans değerinin altında ölçümler) istenen spesifikasyonların karşılanmadığı görüldü.

Sonuç: Mini-Endo-Bloc, cetvel ve delik ölçümlerinde istenilen kalite standardını tamamen karşıladı. Resident istenilen kalite standardını karşılamadı.

Makale gönderiliş tarihi: 28 Aralık 2019; Yayına kabul tarihi: 7 Nisan 2020 * Iletişim: Esma Sarıçam, Ankara Yıldırım Beyazıt Üniversitesi, Diş Hekimliği

Fakültesi, Endodonti Anabilim Dalı, Ankara, Türkiye

E-posta: dt.esmasaricam@gmail.com

\begin{abstract}
Anahtar Kelimeler: Ayarlama; endodonti; ölçüm
\end{abstract}
Kaynak Göstermek İçin: Yücel O, Sarıçam E, Altunkaynak B, Kayaoğlu G. İki farklı endodontik cetvelin (endoblok) cetvel ve kalibrasyon deliklerinin ölçüm doğruluklarının incelenmesi. Acta Odontol Turc 2020;37(3):84-90

Editör: Mügem Gürel, Gazi Üniversitesi, Ankara, Türkiye

YAYıN HAKKI: () 2020 Yücel ve ark. Bu eserin yayın hakkı Creative Commons Attribution License ile ruhsatlandırılmıştır. Sınırsız kullanım, dağıtım ve her türlü ortamda çoğaltım, yazarlar ve kaynağın belirtilmesi kaydıyla serbesttir.

FinANSAL DESTEK: Bulunmamaktadır.

ÇıKAR ÇATıŞMASı: Bulunmamaktadır.

[The abstract in English is at the end of the manuscript]

\section{Giriş}

Endodontik tedavi, nekrotik-enfekte veya iltihaplı pulpanın veya elektif amaçlarla sağlıklı pulpanın çıkartılarak kök kanal sisteminin doku artıklarından ve mikroorganizmalardan arındırılması ve yeniden kontaminasyonunu önleyecek şekilde sızdırmaz olarak doldurulması esaslarını içerir. Bu noktada, endodontik çalışma boyu kavramı söz konusu olmaktadır. Endodontik çalışma boyu, kanal sisteminin apikalindeki en dar çap (apikal konstriksiyon/minör apikal çap) ile koronalde referans bir nokta arasındaki tekrar edilebilir mesafeyi ifade eder. ${ }^{1,2}$

Endodontik çalışma boyunun doğru tespit edilmesi ve tedavi süresince bu doğruluğun korunması tedavinin başarısı için gereklidir. Çalışma boyu olması gerekenden kısa belirlenirse kök kanalı içerisinde artık nekrotik ve enfekte pulpa dokusu veya hiperaljezik sinir uçları barındıran iltihaplı canlı pulpa dokusu kalmasına neden olabilmektedir. Olması gerekenden uzun belirlenirse de periapekste mekanik hasar ve olası irrigan ekstrüzyonuna bağlı olarak kimyasal hasar meydana gelebilmekte ve taşkın kök kanal dolgusu söz konusu olabilmektedir. ${ }^{2-4}$ Çalışma boyunun hatalı belirlendiği bu her iki durumda da post-operatif semptomlar artar ve periapikal iyileşme süreci olumsuz yönde etkilenir. 5,6

Endodontik çalışma boyunun doğru saptanmasında, elektronik apeks bulucular en büyük yardımcımızdır. Koronalde bir tüberkül tepesi, insizal kenar veya kavite 


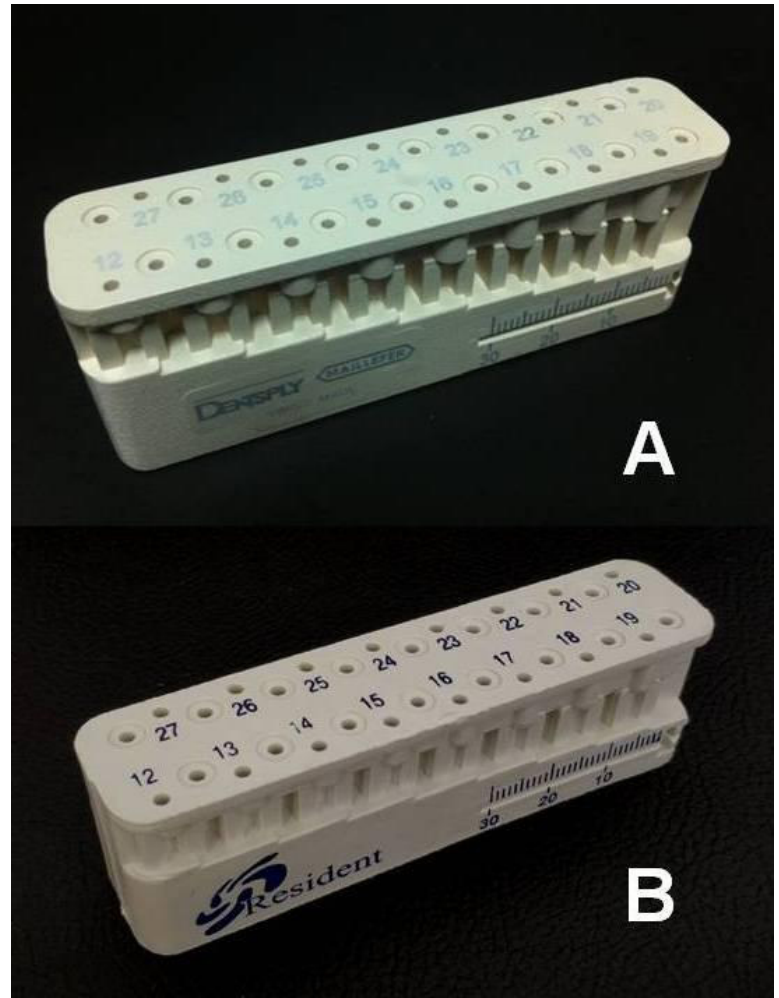

Resim 1. Çalışmada test edilen bir yüzünde cetvel, üst kısmında ise kalibrasyon delikleri bulunan endobloklar; (A) Mini-Endo-Bloc (Dentsply-Maillefer, Ballaigues, İsviçre), (B) Resident (Kibar Dental, İstanbul, Türkiye)

marjini gibi değişmeyecek bir noktanın seçilerek tekrarlanabilir bir referans noktası olarak alınması ve bu noktanın da çalışma boyu ile birlikte kaydedilmesi çalışma boyunun doğru sürdürülebilmesi için gereklidir. ${ }^{1}$ Diğer taraftan bunlar kadar önemli bir konu ise; apikal daralım ve koronal referans arası mesafenin doğru transfer edilmesi ve ölçülmesidir. Güvenilir lastik stoperler ve eğe şaftında bulunan kalibrasyon halkaları bu mesafenin transfer edilmesinde faydalıdırlar. ${ }^{7}$ Ölçümde ise yaygın olarak endoblok olarak adlandırılan endodontik cetvellerden yararlanılmaktadır.
Doğruluk (accuracy), bir ölçüm değerinin gerçek değere yakınlığını ifade eden bir terimdir. Endoblokların ölçümlerinin doğruluğu yukarıda bahsedilen nedenlerle önemlidir. Farklı endoblok markalarının doğruluğu üzerine yapılmış az sayıda çalışma vardır; bu çalışmalarda endoblokların doğruluk seviyelerinin düşük olduğu gösterilmiştir. ${ }^{8-11}$ Yurtdışından ithal edilen endoblokların yanısıra ülkemizde yerli üretim endobloklar da bulunmaktadır. Ancak bunların doğruluğuna ait yayımlanmış herhangi bir bilgi yoktur.

$\mathrm{Bu}$ çalışmanın amacı, yerli üretim bir endobloğun doğruluğunun incelenmesidir. Kontrol amacıyla bir de uluslararası bir firmanın ürünü incelenmiştir.

\section{Gereç Ve YönTEM}

\section{Endobloklar}

Mini-Endo-Bloc (Dentsply-Maillefer, Ballaigues, İsviçre; Lot no: 1579929; 2019-05) ve yerli üretim Resident (Kibar Dental, İstanbul, Türkiye; Lot no: Bilinmiyor; İmalatçıdan 27 Eylül 2018'de temin edildi) marka endobloklardan üçer adet alınarak değerlendirildi. Her iki marka endobloğun bir yüzünde bir cetvel ve üzerinde eğelerin boy ayarlamasını yapmak üzere bir seri kalibrasyon deliği mevcuttu (Resim 1).

\section{Uzunluk ölçümleri}

Uzunluk ölçümlerinde CE sertifikasyonu bulunan 0.01 $\mathrm{mm}$ hassasiyetinde (100 mm uzunluğun altında +/- 0.02 $\mathrm{mm}$ doğruluğa sahip) bir elektronik kumpas kullanıldı (TorQ, Shenzhen, Guangdong, Çin). Endoblokların cetvelleri üzerinde bulunan milimetre çizgileri doğrudan kumpas ile ölçüldü (Resim 2). Deliklerin derinlikleri ise, $25 \mathrm{~mm}$ veya $31 \mathrm{~mm}$ uzunluğunda lastik stoperli \#40 Ktipi bir eğeye transfer edilerek yine kumpas ile ölçüldü (Resim 2). Her ölçümden önce kumpas sıfır noktasına getirilerek 0.00 mm'ye kalibre edildi. Ölçümleyenin etkilenmemesi için kumpasın dijital göstergesi ölçüm tamamlanana kadar maskelendi. Her bir paralel $5 \mathrm{kez}$ ölçüldü. Ölçümler, tek bir araştırmacı tarafından gerçekleştirildi.

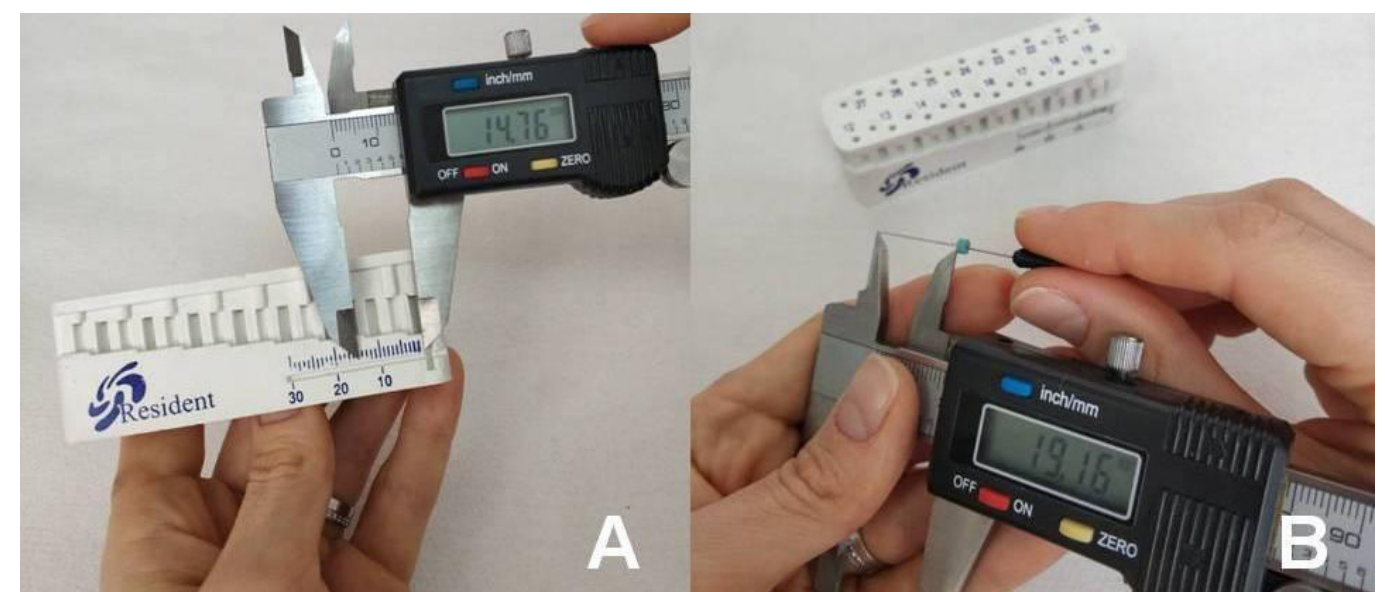

Resim 2. Endoblok ölçümlerinde elektronik kumpasın kullanımı; (A) Cetvelin doğrudan kumpas ile ölçümü,

(B) Delik derinlik boyunun eğeye transfer edilerek kumpas ile ölçümü 
Tablo 1. Endobloklardaki cetvel çizgileri için spesifikasyon ve kontrol sınırları

\begin{tabular}{|c|c|c|c|c|c|c|}
\hline \multirow[b]{3}{*}{ RD } & \multicolumn{2}{|c|}{ Spesifikasyon sınırları } & \multicolumn{4}{|c|}{ Kontrol sınırları } \\
\hline & \multirow[b]{2}{*}{ LSL } & \multirow[b]{2}{*}{ USL } & \multicolumn{2}{|c|}{ Mini-Endo-Bloc } & \multicolumn{2}{|c|}{ Resident } \\
\hline & & & LCL & UCL & LCL & UCL \\
\hline 12 & 11.7 & 12.3 & 12.082 & 12.247 & 12.077 & 12.235 \\
\hline 13 & 12.7 & 13.3 & 13.078 & 13.228 & 13.119 & 13.242 \\
\hline 14 & 13.7 & 14.3 & 14.079 & 14.218 & 14.081 & 14.227 \\
\hline 15 & 14.7 & 15.3 & 15.084 & 15.242 & 15.074 & 15.213 \\
\hline 16 & 15.7 & 16.3 & 16.148 & 16.214 & 16.144 & 16.263 \\
\hline 17 & 16.7 & 17.3 & 17.158 & 17.235 & 17.093 & 17.204 \\
\hline 18 & 17.7 & 18.3 & 18.079 & 18.222 & 18.100 & 18.254 \\
\hline 19 & 18.7 & 19.3 & 19.134 & 19.226 & 19.097 & 19.267 \\
\hline 20 & 19.7 & 20.3 & 20.041 & 20.207 & 20.138 & 20.223 \\
\hline 21 & 20.7 & 21.3 & 21.085 & 21.215 & 21.092 & 21.219 \\
\hline 22 & 21.7 & 22.3 & 22.079 & 22.202 & 22.172 & 22.299 \\
\hline 23 & 22.7 & 23.3 & 23.077 & 23.204 & 23.202 & 23.330 \\
\hline 24 & 23.7 & 24.3 & 24.039 & 24.158 & 24.173 & 24.284 \\
\hline 25 & 24.7 & 25.3 & 25.006 & 25.182 & 25.192 & 25.364 \\
\hline 26 & 25.7 & 26.3 & 26.111 & 26.207 & 26.247 & 26.355 \\
\hline 27 & 26.7 & 27.3 & 27.068 & 27.187 & 27.230 & 27.361 \\
\hline 28 & 27.7 & 28.3 & 28.104 & 28.223 & 28.259 & 28.401 \\
\hline 29 & 28.7 & 29.3 & 29.044 & 29.233 & 29.225 & 29.349 \\
\hline 30 & 29.7 & 30.3 & 30.001 & 30.159 & 30.263 & 30.391 \\
\hline
\end{tabular}

LSL: Lower Specification Limit (alt spesifikasyon sınırı); USL: Upper Specification Limit (üst spesifikasyon sınırı); LCL: Lower Control Limit (alt kontrol sınırı); UCL: Upper Control Limit (üst kontrol sınırı); RD: Referans değer

\section{Analizler}

Her bir endoblok markasının ölçüm kalitesinin incelenmesi için istatistiksel kontrol sınırları ile spesifikasyon sınırları karşılaştırıldı. Spesifikasyon sınırlarının aşıldığı durumlar için kontrol grafikleri çizilerek kontrol dışı ölçümler ayrıca incelendi. Çalışmada 3 standart sapma genişliği dikkate alındığından \%99'luk güven düzeyi ile çalışıldı.

Spesifikasyon sınırları, ürün üzerinde belirtilen referans değerler dikkate alınarak 3 standart sapma (sigma) genişliğinde hesaplanır. ${ }^{12}$ Kontrol sınırları ise, ürünün test edilmesi sırasında elde edilen ölçümlerden hesaplanır. Kaliteli bir üründe kontrol sınırlarının spesifikasyon sınırlarını aşmaması istenir.

\section{Spesifikasyon sınırlarının hesaplanması}

Spesifikasyon sınırlarının (Specification Limits; SL) hesaplanması için gerekli olan referans değerleri ürünler üzerinde belirtilmiştir. Endobloklar üzerindeki delikler için referans değerler, 12.0-27.5 mm arasında 0.5 mm'lik adım büyüklükleriyle; cetvel çizgileri için referans değerler ise $12-30 \mathrm{~mm}$ arasında $1 \mathrm{~mm}$ 'lik adım büyüklükleriyle verilmiştir. Ancak, üreticiler, ürün ambalajlarında veya ürüne ait internet sayfalarında standart sapmaya ilişkin bir bilgi sunmamaktadır. ${ }^{13,14}$ Bu nedenle, standart sapma değerleri tüm test ölçümleri kullanılarak delikler ve çizgiler için $0.1 \mathrm{~mm}$ olarak tahmin edilmiştir. Örneğin, endoblok üzerindeki ilk delik (referans değeri 12.0) için spesifikasyon sınırları $S L=12.0 \pm 3(0.1)$ olarak hesaplandı ve bu durumda LSL=11.7 mm (Lower Spe- cification Limit [alt spesifikasyon sınırı]) ve USL=12.3 $\mathrm{mm}$ (Upper Specification Limit [üst spesifikasyon sınıri]) olarak elde edildi.

\section{Kontrol sınırlarının hesaplanması}

Kontrol sınırlarının (Control Limits; CL) hesaplanması test ölçümleri üzerinden yapılır. Ortalama kontrol sınırlarının hesaplanmasında kullanılan formül aşağıda verilmiştir. ${ }^{12}$

$$
C L=\overline{\bar{X}} \pm A_{3} \bar{S}
$$

Formülde $\overline{\bar{X}}$ ortalamaların ortalamasını, $A_{3}$ örneklem büyüklüğüne bağlı bir sabiti ve $\bar{S}$ standart sapmaların ortalamasını göstermektedir. Bu çalışmada her bir paralel için 5 ölçüm alındığından $A_{3}=1.427$ olarak alınır. ${ }^{12}$ Örneğin, Dentsply marka endoblokta referans değeri 12.0 olan delik için 5 tekrarlı üç ürüne ait elde edilen ölçümlerin ortalamaları sırasıyla 12.040, 12.134, 12.168 ve standart sapmaları sırasıyla $0.104,0.061,0.046$ 'dır. Bu durumda $\overline{\bar{X}}=(12.040+12.134+12.168) / 3=12.114$ $\mathrm{mm}$ ve $\bar{S}=(0.104+0.061+0.046) / 3=0.0703 \mathrm{~mm}$ olarak tahmin edilir. Bu değerler ile kontrol sınırları $C L=12.114 \pm 1.427(0.070)$ 'den $L C L=12.015$ mm (Lower Control Limit [alt kontrol sınırı]) ve UCL $=12.213 \mathrm{~mm}$ (Upper Control Limit [üst kontrol sınırı]) olarak hesaplandı. 


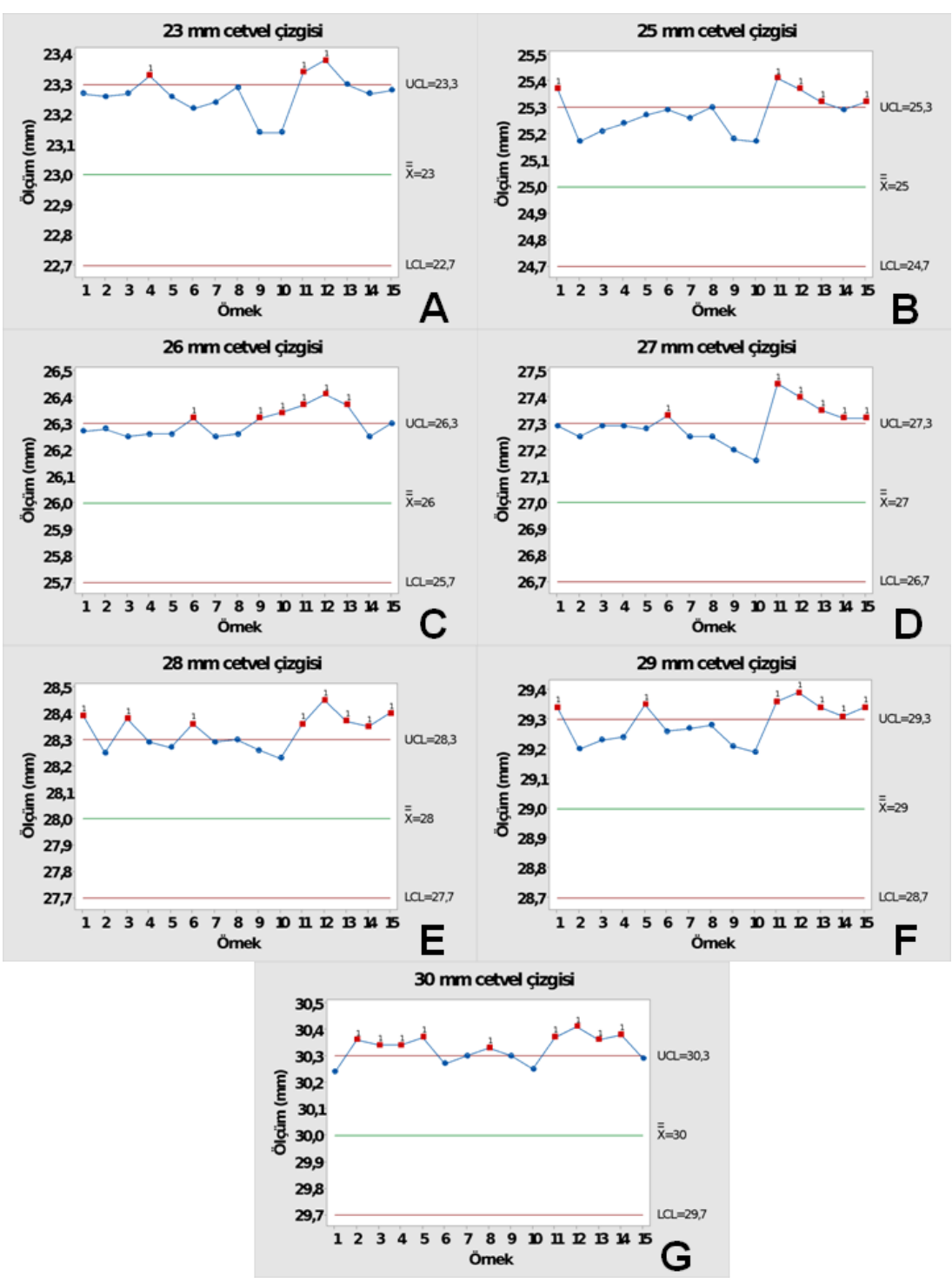

Şekil 1. Spesifikasyonların sağlanmadığı cetvel çizgilerinde Resident endoblok ölçümlerinin kontrol grafikleri; (A) $23 \mathrm{~mm}$ çizgisi için, (B) $25 \mathrm{~mm}$ çizgisi için, (C) $26 \mathrm{~mm}$ çizgisi için, (D) $27 \mathrm{~mm}$ çizgisi için, (D) $28 \mathrm{~mm}$ çizgisi için, (F) $29 \mathrm{~mm}$ çizgisi için, (G) $30 \mathrm{~mm}$ çizgisi için

\section{BULGULAR}

\section{Endoblok üzerindeki cetvel çizgilerine ilişkin inceleme}

Dentsply marka endoblok tüm çizgilerde istenilen kalite standardını karşıladı (Tablo 1). Diğer yandan, Resident'in 23, 25, 26, 27, 28, 29, 30 mm çizgilerinde istenilen spesifikasyonları karşılamadığı görüldü. Bu çizgiler için Resident'e ait ölçümlerin kontrol grafikleri Şekil 1'de verilmiştir.

Şekil 1 incelendiğinde, spesifikasyonların sağlanamadığı çizgiler için Resident ölçümlerinin tamamının referans değerinin üstünde olduğu görülmektedir. Bu çizgilerden, $23 \mathrm{~mm}$ çizgisinde 15 ölçümden 3'ünün spesifikasyon sınırlarının dışında olduğu ve bunun oranının $(3 / 15)=0.20$, yani $\% 20$ olduğu görülmektedir. Bu oranlar $25-30 \mathrm{~mm}$ çizgilerinde $\% 33$ ile $\% 60$ arasında değişmektedir. Örneğin, 30 mm çizgisinde, 5 ölçümden 3'ü hatalıdır.

\section{Endoblok üzerindeki deliklere ilişkin inceleme}

Mini-Endo-Bloc tüm deliklerde istenilen kalite standardını karşıladı (Tablo 2). Diğer yandan, Resident, 15.0, 18.0, 18.5 ve 19.0 numaralı deliklerde istenilen spesifikasyonları sağlamadı. Bu delikler için Resident'e ait ölçümlerin kontrol grafikleri Şekil 2'de verilmiştir.

Şekil 2 incelendiğinde, spesifikasyonların sağlanmadığı delikler için Resident ölçümlerinin tamamının referans değerinin altında olduğu görülmektedir. Bu deliklerden, 15.0 ve 18.0 numaralı deliklerde 15 ölçümden 2'sinin spesifikasyon sınırlarının dışında olduğu ve bunun oranının $(2 / 15)=0.1333$, yani \%13.33 olduğu görülmektedir. Bu oran 18.5 numaralı delik için \%26.67 iken 19.0 numaralı delik için \%80'dir. Bir başka ifadeyle 19.0 numaralı delik için ortalama 5 ölçümden 4'ü hatalıdır. 
Tablo 2. Endobloklardaki delikler için spesifikasyon ve kontrol sınırları

\begin{tabular}{|c|c|c|c|c|c|c|}
\hline \multirow[b]{3}{*}{ RD } & \multicolumn{2}{|c|}{ Spesifikasyon sınırları } & \multicolumn{4}{|c|}{ Kontrol sınırları } \\
\hline & \multirow[b]{2}{*}{ LSL } & \multirow[b]{2}{*}{ USL } & \multicolumn{2}{|c|}{ Mini-Endo-Bloc } & \multicolumn{2}{|c|}{ Resident } \\
\hline & & & LCL & UCL & LCL & UCL \\
\hline 12.0 & 11.7 & 12.3 & 12.015 & 12.213 & 11.873 & 12.165 \\
\hline 12.5 & 12.2 & 12.8 & 12.437 & 12.737 & 12.384 & 12.633 \\
\hline 13.0 & 12.7 & 13.3 & 13.011 & 13.153 & 12.825 & 13.083 \\
\hline 13.5 & 13.2 & 13.8 & 13.508 & 13.692 & 13.307 & 13.537 \\
\hline 14.0 & 13.7 & 14.3 & 13.944 & 14.198 & 13.714 & 13.879 \\
\hline 14.5 & 14.2 & 14.8 & 14.444 & 14.652 & 14.290 & 14.750 \\
\hline 15.0 & 14.7 & 15.3 & 14.944 & 15.125 & 14.698 & 14.878 \\
\hline 15.5 & 15.2 & 15.8 & 15.437 & 15.648 & 15.320 & 15.540 \\
\hline 16.0 & 15.7 & 16.3 & 15.954 & 16.100 & 15.770 & 16.035 \\
\hline 16.5 & 16.2 & 16.8 & 16.405 & 16.644 & 16.357 & 16.526 \\
\hline 17.0 & 16.7 & 17.3 & 16.986 & 17.109 & 16.761 & 16.930 \\
\hline 17.5 & 17.2 & 17.8 & 17.444 & 17.628 & 17.298 & 17.467 \\
\hline 18.0 & 17.7 & 18.3 & 17.995 & 18.121 & 17.692 & 17.816 \\
\hline 18.5 & 18.2 & 18.8 & 18.471 & 18.664 & 18.153 & 18.292 \\
\hline 19.0 & 18.7 & 19.3 & 19.016 & 19.131 & 18.560 & 18.737 \\
\hline 19.5 & 19.2 & 19.8 & 19.466 & 19.620 & 19.283 & 19.417 \\
\hline 20.0 & 19.7 & 20.3 & 19.974 & 20.078 & 19.993 & 20.200 \\
\hline 20.5 & 20.2 & 20.8 & 20.422 & 20.610 & 20.405 & 20.574 \\
\hline 21.0 & 20.7 & 21.3 & 20.943 & 21.158 & 20.884 & 20.991 \\
\hline 21.5 & 21.2 & 21.8 & 21.464 & 21.695 & 21.433 & 21.626 \\
\hline 22.0 & 21.7 & 22.3 & 21.980 & 22.137 & 21.901 & 22.120 \\
\hline 22.5 & 22.2 & 22.8 & 22.483 & 22.648 & 22.492 & 22.712 \\
\hline 23.0 & 22.7 & 23.3 & 22.969 & 23.165 & 22.877 & 23.112 \\
\hline 23.5 & 23.2 & 23.8 & 23.360 & 23.714 & 23.412 & 23.647 \\
\hline 24.0 & 23.7 & 24.3 & 23.921 & 24.079 & 23.901 & 24.112 \\
\hline 24.5 & 24.2 & 24.8 & 24.383 & 24.656 & 24.450 & 24.669 \\
\hline 25.0 & 24.7 & 25.3 & 24.932 & 25.108 & 24.901 & 25.132 \\
\hline 25.5 & 25.2 & 25.8 & 25.448 & 25.637 & 25.387 & 25.637 \\
\hline 26.0 & 25.7 & 26.3 & 25.976 & 26.103 & 25.895 & 26.114 \\
\hline 26.5 & 26.2 & 26.8 & 26.412 & 26.705 & 26.394 & 26.632 \\
\hline 27.0 & 26.7 & 27.3 & 26.962 & 27.170 & 26.829 & 27.094 \\
\hline 27.5 & 27.2 & 27.8 & 27.444 & 27.637 & 27.386 & 27.567 \\
\hline
\end{tabular}

LSL: Lower Specification Limit (alt spesifikasyon sınırı); USL: Upper Specification Limit (üst spesifikasyon sınırı);

LCL: Lower Control Limit (alt kontrol sınırı); UCL: Upper Control Limit (üst kontrol sınırı); RD: Referans değer
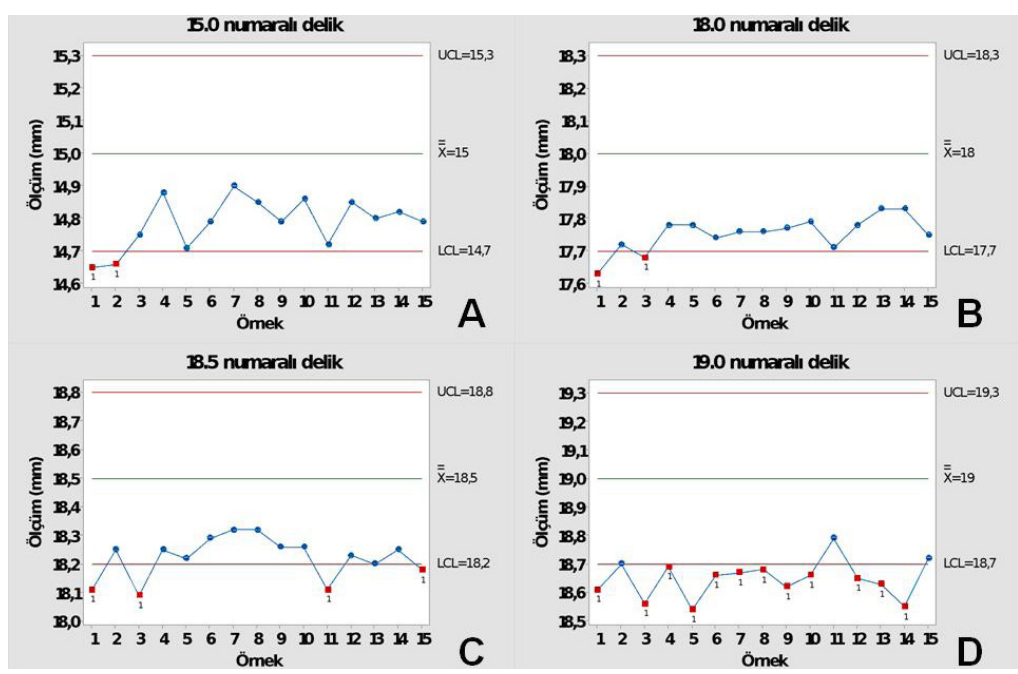

Şekil 2. Spesifikasyonların sağlanmadığı deliklerde Resident endoblok ölçümlerinin kontrol grafikleri;

(A) 15.0 no'lu delik için, (B) 18.0 no'lu delik için, (C) 18.5 no'lu delik için, (D) 19.0 no'lu delik için 


\section{TARTIŞMA}

$\mathrm{Bu}$ çalışmanın ana bulgusu, yerli üretim endoblok Resident'in cetvel ve delik doğruluklarının bazı değerler için spesifikasyon sınırları dışında olduğudur. Buna karşın, kontrol olarak kullanılan Mini-Endo-Bloc'un tamamen spesifikasyon sınırları içerisinde olduğu bulundu.

Bu çalışma, endodontik cetvellerin doğruluğunu test eden ender çalışmalardan biridir. Daha önce yapıımış az sayıda çalışma, Brezilya kaynaklıdır. ${ }^{8-11}$ Bu çalışmalarda çoğunlukla Brezilya menşeili ürünler ve bunların yanı sıra tanınmış uluslararası dental materyal üreticilerinin ürünleri test edilmiştir. Bu çalışmalardan biri olan Victorino ve arkadaşlarının ${ }^{10}$ çalışmasında dört farklı Brezilya menşeili ürün üzerinde cetvelin yalnızca 20 mm noktası ölçülmüştür ve hiçbirinin tam doğruluğa sahip olmadığı bulunmuştur. Benzer şekilde Pimentel Lins ve ark. ${ }^{11}$ da çoğunluğu Brezilya menşeili olan 10 cetvel üzerinde yalnızca cetvelin $30 \mathrm{~mm}$ noktasını ölçmüş ve tümünde doğruluk hataları bulmuşlardır. Bununla beraber Dentsply-Maillefer tarafından üretilen cetvelin, içlerinden doğruluk oranı en yüksek olan cetvel olduğunu bildirmişlerdir. Yaptığımız çalışmanın verileri incelendiğinde de Dentsply-Maillefer ürününün cetvel kısmının doğruluğunun yüksek olduğu söylenebilir. Buna karşın, Alencar ve arkadaşlarının ${ }^{9}$ profil projektörü ile yaptıkları ölçüm çalışmasında ise Maillefer ürünü endodontik cetvelin doğruluğunun diğer Brezilya menşeili ürünlerden daha düşük olduğu bildirilmiştir.

Çalışmamız daha önceki çalışmalardan farklı olarak kalibrasyon deliklerinin ölçümünü yapan ilk ve tek çalışmadır. Daha önce aynı yerli firmanın ENDOBLOK (Kibar Dental) markasını test etmiş, hem cetvel ve hem de deliklerde sapmalar tespit etmiş ve imalatçı firmaya durumu bildirmiştik..$^{15}$ Firmanın bunun üzerine yaptığı revizyonun hala hatalar içerdiği bu çalışmada görülmektedir.

Bu çalışmada, spesifikasyonların sağlanamadığı cetvel çizgileri için Resident'in bir uzunluğu gerçekte olandan daha kısa ölçme eğiliminde olduğu anlaşılmaktadır. Yine, spesifikasyonların sağlanamadığı delikler için Resident'in olması gerekenden daha küçük uzunluklar sunma eğiliminde olduğu anlaşılmaktadır. Endodontik tedavide işlem sırası göz önünde bulundurulduğunda, önce cetvel üzerinde ölçüm yapılacak ve ardından elde edilen ölçümler delikler yoluyla sürdürülecektir. Dolayısıyla bu iki ardışık aşamada gerçek endodontik çalışma uzunluğunun gitgide kaybı söz konusu olacaktır. Bu kaybın endodontik tedaviye yansımasının, gerekenden kısa kanal preparasyonları şeklinde olacağı düşünülmektedir. Bunun klinik sonucunun da yetersiz kök kanal debridmanı ve dezenfeksiyonu ve kısa kanal dolumu şeklinde olacağı öngörülmektedir.

Bu çalışmada hipotez testi yapılmamıştır. Dolayısıyla güç hesaplamasına dayalı bir minimum örneklem büyüklüğü belirlenmesine intiyaç duyulmamıştır. Çalışmamızın kısıtııı̆̆ı ölçümlerin tek bir kişi tarafından yapılmış olmasıdır. Buna karşın, araştıııcının yanlı ölçüm yapmasını engellemek amacıyla ölçüm ekranı kapatılı ve ölçüm aleti her seferinde sıfır kalibrasyonuna getirildi. Bundan sonraki çalışmalarda birden fazla gözlemcinin dahil edilerek tutarlıı̆̆ın göz önünde bulundurulması ve daha fazla sayıda örneğin test edilmesi tavsiye edilir.

\section{SonUÇ}

Yerli üretim endoblok Resident'in bazı cetvel ve delik değerlerinin spesifikasyon sınırlarının dışında olduğu, buna karşın Mini-Endo-Bloc'un tamamen spesifikasyon sınırları içerisinde olduğu görüldü.

\section{KAYNAKLAR}

1. Tınaz AC. Kanal tedavisinde çalışma boyutu. GÜ Diş Hek Fak Derg 2001;18:31-37.

2. Ekici MA, Helvacıoğlu Kıvanç B, Ekici A. Genişletilmiş apikal foramenlere sahip dişlerde multi-frekans elektronik apeks bulucuların doğruluğunun karşılaştırılması: ex vivo. Acta Odontol Turc 2018;35:1722.

3. Koçak S, Koçak MM, Sağlam BC. Efficiency of 2 electronic apex locators on working length determination: A clinical study. J Conserv Dent 2013;16:229-32.

4. Demir E, Sağlam BC, Koçak S, Koçak MM, Aktemur Türker S. Farklı preparasyon genişliklerinde iki elektronik apeks bulucu cihazın doğruluğunun değerlendirilmesi. Acta Odontol Turc 2015;32:47-50.

5. Sjogren U, Hagglund B, Sundqvist G, Wing K. Factors affecting the long-term results of endodontic treatment. J Endod 1990;16:498-504.

6. Ricucci D, Langeland K. Apical limit of root canal instrumentation and obturation, part 2. A histological study. Int Endod J 1998;31:394-409.

7. Lingard CN, Frick KJ, Walker MP. Comparison of Accuracy of Calibration Ring Placement on 4 Different Endodontic Files. J Endod 2015;41:1892-4.

8. Andrade LP, Pinheiro JT. Avaliação das réguas para odontometria eletrônica: avaliação comparativa do comprimento de três réguas milimetradas utilizadas durante o tratamento endodôntico. RGO - Rev Gaúcha Odontol 1993;41:17-9.

9. Alencar AHG, Bruno KF, Arruda MF, Barnabé W. Avaliação da padronização e da precisão das réguas endodônticas milimetradas utilizadas para odontometria em endodontia. Rev Odont Unesp 2005;34:79-83

10. Victorino FR, Lustosa-Pereira A, Bernardineli N, Garcia RB, Moraes IG, Bramante CM. Analysis of accuracy of endodontic millimeter rulers of different commercial brands. RGO - Rev Gaúcha Odontol 2012;60:305-8.

11. Pimentel Lins R, Pinto Menezes LV, Correia de Araújo RP, Albergaria da Silva SJ, Cardeal Mendes CM. Exatidão e precisão das réguas milimetradas utilizadas durante procedimentos endodônticos. Rev Ciênc Méd Biol 2015;14:286-92.

12. Montgomery DC. Introduction to Statistical Quality Control. 2nd ed. New York: John Wiley \& Sons; 1991. p. 202, 233, Appendix VI.

13. Kibar Dental [Internet]. İstanbul [cited: 2019 Dec 17] Endoblok. Available from: https://www.kibardental.com/Endoblok,PR-140.html

14. Dentsply Sirona Endodontics [Internet]. Ballaigues [cited: 2019 Dec 17] Mini-Endo-Bloc. Available from: http://www.dentsplymaillefer.com/ product/mini-endo-bloc

15. Yücel O, Sarıçam E, Kayaoğlu G. İki farklı endodontik cetvelin (endoblok) milimetrik doğruluğunun incelenmesi. Poster sunumu: 6. Uluslararası Endodonti Sempozyumu; 2015 Mar 6-8; Erzurum, Türkiye. 


\section{Examination of measurement accuracy of the ruler and calibration holes of two different endodontic rulers (endoblocks)}

\begin{abstract}
OBJECTIVE: Endoblock is an odontometric instrument that helps to determine and maintain the working length in endodontic practice. The aim of this study was to evaluate the millimetric accuracy of two different endoblocks, one of which is domestic-manufacture.

MATERIALS AND MEthod: Three endoblocks (six in total) from each brand which are Mini-Endo-Bloc (Dentsply-Maillefer, Ballaigues, Switzerland) and Resident (Kibar Dental, Istanbul, Turkey) were obtained. The milimetric marks located on the ruler side of the endoblock (between 12-30) was measured using an electronic caliper with a $0.01 \mathrm{~mm}$ precision. The depth of the file-length-calibration holes located on the upper side of the endoblock (between 12.0-27.5) was measured using the same caliper but by
\end{abstract}

means of transferring the depth to a \#40 file with silicone stopper. Each parallel was measured five times. Statistical control limits and specification limits were compared to examine the measurement quality of each endoblock brand. The specification limits were calculated in 3 standard deviation (sigma) widths taking the reference values into account indicated on the product. Control limits were calculated utilizing the measurements obtained during product testing. If the control limits exceeded the specification limits, it was considered an error.

RESULTS: No errors were observed in the ruler and calibration holes of the Mini-Endo-Bloc. Resident's 23, 25-30 mm ruler lines (measurements above the reference value) and 15.0, 18.0, 18.5 and 19.0 holes (measurements below the reference value) failed to meet the desired specifications.

Conclusion: The Mini-Endo-Bloc fully met the required quality standards in ruler and hole measurements. Resident did not meet the required quality standard.

KEYWORDS: Calibration; endodontics; measurement 